\title{
O futuro do trabalho pós Covid-19
}

\author{
The future of work after Covid-19 \\ El futuro del trabajo posterior a covid-19
}

José Paulo Zeetano Chahad ${ }^{1}$

\section{Resumo \\ CHAHAD, José Paulo Zeetano. O futuro do trabalho pós Covid-19. Rev. C\&Trópico, v. 45, n. 1, p. 85-113, 2021. DOI: https://doi.org/10.33148/cetropicov45n1(2021)art6}

Desde o final do ano de 2019, a humanidade convive com a pandemia da COVID-19, que faz parecer que estamos próximos do Apocalipse, tamanha é a velocidade de contaminação do vírus, deixando um grande rastro de infectados e de mortos por onde passa. Esta pandemia trouxe consigo profundas consequências no campo econômico, na vida social e cultural, no modo de vida tradicional dos indivíduos e das famílias, na vida profissional, e no relacionamento entre os atores sociais, afetando, principalmente, o mercado de trabalho. Este artigo abordará o futuro do trabalho pós COVID-19. Para tanto se fundamentará na vasta literatura já existente sobre o tema. Inicialmente será apresentada uma visão geral da origem e da natureza das modificações que ocorrerão no mundo do trabalho, devido ao impacto global da pandemia, e da recessão que se seguiu. Três tópicos serão abordados, pois são aqueles que mais tem se destacado sob a ótica do futuro do trabalho: (a) trabalho remoto, home office e teletrabalho; (b) tecnologia, digitalização e automação; e (c) produtividade do trabalho. A constatação geral é que a COVID-19 aumentou o risco, bem como elevou os custos (sociais e econômicos) do contato físico entre os seres humanos. Como consequência acelerou os processos de automação, do trabalho remoto, do uso da inteligência artificial, da digitalização e da robotização, todos culminando por promover uma redução geral na demanda de trabalho (elevando o desemprego), contribuindo, assim, para diminuir o ritmo de crescimento dos salários. O efeito mais perverso seja, talvez, o fato de que o isolamento social tem causado na educação das populações jovens. Isto tem levado à evasão, e ao baixo rendimento escolar, juntamente com a erosão do capital humano provocado pelo aumento do desemprego de longo prazo. Estes tem sido fortes elementos a induzirem ao baixo nível de crescimento da produtividade do trabalho, quando não da sua estagnação. Todos estes impactos somados parecem estar levando a um mundo ainda mais desigual, afetando negativamente o desenvolvimento humano, bem como promovendo um avanço ainda maior dos níveis de pobreza.

Palavras-chave: Mercado de Trabalho. COVID-19. Teletrabalho. Trabalho Remoto. Automação. Produtividade do Trabalho.

1 Professor Titular da FEA/USP (aposentado) e Pesquisador Sênior da Fundação Instituto de Pesquisas Econômicas (FIPE). E-mail: jpchahad@usp.br Orcid: https://orcid.org/0000-0002-9421-3757. O autor agradece à Secretária Amira Canário pelo competente trabalho de elaboração das figuras, gráficos e tabelas deste texto. Erros e omissões são de responsabilidade do autor. 


\section{Abstract}

CHAHAD, José Paulo Zeetano. El futuro del trabajo posterior a covid-19. Rev. C\&Trópico, v. 45, n. 1, p. 85-113, 2021. DOI: https://doi.org/10.33148/cetropicov45n1(2021)art6

Since the end of 2019, humanity has lived with the pandemic of COVID-19, which makes it seems that we are close to the Apocalypse; such is the speed of contamination of the virus, leaving a large trail of infected and dead wherever it goes. This pandemic has had profound consequences in the economic field, in social and cultural life, in the traditional way of life of individuals and families, in professional life, and in the relationship between social actors, affecting mainly the labor market. This article will address the future of work post-COVID-19. To do so, it will be based on the vast existing literature on the subject. Initially, an overview of the origin and nature of the changes that has occurred in the world of work will be showed, due to the global impact of the pandemic, and the recession that followed. Three topics will be addressed, as they are the ones that have stood out the most from the perspective of the future of work: (a) remote work, home office and telework; (b) technology, digitization and automation; and (c) labor productivity. The general finding is that COVID-19 increased the risk, as well as the costs (social and economic) of physical contact between human beings. The consequence is to accelerated the processes of automation, remote work, the use of artificial intelligence, digitalization and robotization, all culminating in promoting a general reduction in the demand for work (increasing unemployment), thus contributing to reduce the pace of the wage growth. The most perverse effect is, perhaps, the fact that social isolation has caused on the education of young populations. This has led to dropout, and low school performance, coupled with the erosion of human capital caused by rising long-term unemployment. These have been strong elements to induce the low level of growth in labor productivity, if not its stagnation. All these impacts combined seem to be leading to an even more unequal world, negatively affecting human development, as well as promoting an even greater advance in the levels of poverty.

Keywords: Labor Market. COVID-19. Home Office. Teleworking. Automation. Labor Productivity.

\section{Resumen}

CHAHAD, José Paulo Zeetano. The future of work after Covid-19. Rev. C\&Trópico, v. 45, n. 1, p. 85-113, 2021. DOI: https://doi.org/10.33148/cetropicov45n1(2021)art6

Desde finales de 2019, la humanidad ha vivido con la pandemia de COVID-19, lo que hace que parezca que estamos cerca del Apocalipsis, tal es la velocidad de contaminación del virus, dejando una gran estela de infectados y muertos por donde pasa. Esta pandemia ha tenido profundas consecuencias en el ámbito económico, en la vida social y cultural, en el modo de vida tradicional de las personas y familias, en la vida profesional y en la relación entre actores sociales, afectando 
principalmente al mercado laboral. Este artículo abordará el futuro del trabajo posterior a COVID-19. Para ello, se basará en la vasta literatura existente sobre el tema. Inicialmente, se presentará una descripción general del origen y la naturaleza de los cambios que ocurrirán en el mundo del trabajo, debido al impacto global de la pandemia y la recesión que siguió. Se abordarán tres temas, ya que son los que más se han destacado desde la perspectiva del futuro del trabajo: (a) trabajo a distancia, home office y teletrabajo; (b) tecnología, digitalización y automatización; y (c) productividad laboral. El hallazgo general es que COVID-19 aumentó el riesgo, así como también aumentó los costos (sociales y económicos) del contacto físico entre seres humanos. La consecuencia aceleró los procesos de automatización, trabajo a distancia, uso de inteligencia artificial, digitalización y robotización, todo ello culminando en promover una reducción generalizada de la demanda de trabajo (aumento del desempleo), contribuyendo así a reducir el ritmo de trabajo. El efecto más perverso es, quizás, el hecho de que el aislamiento social ha provocado la educación de poblaciones jóvenes. Esto ha llevado a la deserción escolar y al bajo rendimiento escolar, junto con la erosión del capital humano causada por el aumento del desempleo de larga duración. Estos han sido elementos fuertes para inducir el bajo nivel de crecimiento de la productividad laboral, si no su estancamiento. Todos estos impactos combinados parecen estar conduciendo a un mundo aún más desigual, afectando negativamente el desarrollo humano, además de promover un avance aún mayor en los niveles de pobreza.

Palabras clave: Mercado de Trabajo. COVID-19. Teletrabajo. Trabajo Remoto. Automatización. Productividad del Trabajo.

\section{Introdução}

Desde o final do ano de 2019 a humanidade convive com a pandemia da COVID-19 que nos faz parecer que estamos próximos do apocalipse, tamanha é a velocidade de contaminação do vírus desta doença, deixando um grande rastro de infectados e de mortos por onde passa.

Hoje todas as regiões e países do mundo estão assolados pelo Coronavírus, o patógeno que tem disseminado essa praga. Esta situação, que ainda está longe de acabar, jogou o mundo numa crise sem precedentes, tanto em sua dimensão, quanto em seu escopo, fazendo a comunidade internacional se engajar num esforço coletivo para enfrentar o impacto humano devastador decorrente desta pandemia.

A COVID -19 trouxe consigo profundas e marcantes consequências no campo econômico, na vida social e cultural, no modo de vida tradicional dos indivíduos e das famílias, na vida profissional, no relacionamento entre os atores sociais, afetando, principalmente, o mundo do trabalho.

A recessão global trazida pela pandemia impactou profundamente o mercado de trabalho, fazendo com que milhões de trabalhadores, em todo mundo, estejam 
experimentando mudanças que tem transformado as suas vidas para além do seu trabalho, do seu bem-estar e da sua produtividade. A situação é mais grave do que aparenta devido à assimetria com que a pandemia incide sobre os trabalhadores, impactando com maior velocidade e ferocidade nas populações mais vulneráveis.

Não obstante o amplo espectro de impactos trazidos pela pandemia e pela recessão, as alterações mais substanciais se darão no mercado de trabalho, criando bastante incerteza, bem como acelerando mudanças no futuro do trabalho. Nesta perspectiva, os governos, os trabalhadores, e as empresas terão que contribuir, e se moldarem, aos novos padrões do trabalho humano decorrentes das drásticas mudanças impostas ao status quo atual:

The COVID-19 pandemic will have profound, long-term consequences for our economies and societies, including for the future of work. As part of The Great Reset needed to support the transition to a fairer, more sustainable post-COVID world, companies have a responsibility, and a rare opportunity, to rethink their organizational and workplace structures to invest in their workforces as core drivers of long-term resilience and future success. Having recognized the COVID-19 crisis as a defining leadership and transformation moment, chief people officers and other human resources (HR) and business leaders are now called on to build on what they have learned from the immediate crisis response to reset their organizations' future of work agendas and lead the way towards better and more human-centric work, workplaces and workforces. (World Economic Forum, 2020a, p. 3).

Assim como é difícil se prever como, e quando, a pandemia irá terminar, é igualmente difícil exaurir todos os possíveis desdobramentos sob a ótica do futuro do trabalho. Já existe, contudo, uma vasta literatura sobre o tema, de onde emergem diversos tópicos, havendo uma convergência sobre as transformações no mundo do trabalho sobre vários deles. É sobre isto que este texto tratará, selecionando temas onde o consenso é maior, onde as mudanças são aquelas que, de fato, vieram para ficar.

Inicialmente, porém, será apresentada uma visão geral da origem, e da natureza das modificações que ocorrerão no mundo do trabalho, originadas do impacto global da pandemia. Em seguida, os seguintes tópicos serão abordados: (a) trabalho remoto, home office e teletrabalho; (b) tecnologia, digitalização e automação; e (c) produtividade do trabalho. ${ }^{2}$

2 Diante do amplo espectro de mudanças no mundo do trabalho decorrente da COVID-19 é muito difícil abordar todas eles. Os impactos da pandemia no futuro do trabalho são os mais imediatamente perceptíveis e estão longe de exaurir as alterações promovidas no mercado de trabalho. Temos outros tópicos de muita importância, como questões de desigualdades; efeitos sobre o trabalho formal, informal e precário; considerações sobre o futuro da "gig economy"(mercado de trabalho onde prevalece contratos de curto prazo ou trabalho free-lance); necessidades de novas habilidades, qualificação e treinamento dos trabalhadores, face à aceleração da automação; e o que ocorrerá com o paradigma das relações de trabalho, 
Antes, entretanto, de analisar as consequências da COVID-19, em cada um dos tópicos listados, será apresentada a dimensão atual da pandemia, onde essas transformações estão ocorrendo, e continuarão a ocorrer.

\section{Estatísticas atuais da pandemia da COVID-19}

Embora a apresentação da dimensão global da pandemia não altere as tendências sobre o futuro do trabalho, os dados fornecerão uma ordem de magnitude na qual essas mudanças no futuro do trabalho estão ocorrendo.

\section{Tabela 1: Situação Atual da COVID-19 no Mundo (em 1.000 habitantes)}

\begin{tabular}{|ccccc}
\hline Regiões & No de Casos & $\%$ & No de Mortes & $\%$ \\
\hline Américas & 61.853 & 41,2 & 1.506 & 47,7 \\
\hline Europa & 51.615 & 34,4 & 1.079 & 34,1 \\
\hline Sudoeste da Ásia & 21.847 & 14,6 & 272 & 8,6 \\
\hline Mediterrâneo Oriental & 9.065 & 6,0 & 182 & 5,8 \\
\hline África & 3.301 & 2,2 & 83 & 2,6 \\
\hline Pacífico Ocidental & 2.429 & 1,6 & 37 & 1,2 \\
\hline Total & $\mathbf{1 5 0 . 1 1 0}$ & $\mathbf{1 0 0 , 0 0}$ & $3, \mathbf{1 5 9}$ & $\mathbf{1 0 0 , 0 0}$ \\
\hline
\end{tabular}

Fonte: Painel da WHO Coronavírus Disease (COVID19). Dados do dia 30/04/2021, ás 14h41 CEST.

Em 30/04/2021 o mundo já havia presenciado mais de 150 milhões de pessoas contaminadas pela COVID-19, sendo 41,2\% nas Américas, e 34,4\% na Europa. Destes, 3,2 milhões vieram a morrer, sendo 47,7\%, nas Américas, e 34,1 na Europa, revelando números impactantes da pandemia nessas regiões.

O mais surpreendente desta tabela, e que poderia ser considerada como uma situação altamente improvável refere-se ao baixo contágio (3,5\%), e a pequena letalidade na África (2,5\%). Trata-se de um continente com mais de 1,4 bilhões de habitantes, e se na Europa e nas Américas, a pandemia teve efeitos devastadores, o temor era que haveria uma tragédia ainda maior no continente africano, o mais pobre do planeta. Ademais possui precárias instalações de saneamento e abastecimento de água, um sistema hospitalar incipiente, e que tem sido palco de conflitos internos sangrentos, e, num passado recente, sofreu com as mais variadas epidemias.

Afinal, o que explica esse cenário de aparente resistência ao vírus e que fez com que, pelo menos até agora, não se confirmasse uma tragédia na África, conforme anunciada por pesquisadores e autoridades de saúde? As principais razões são as seguintes: (i) o fato de ter uma população jovem; (ii) a experiência adquirida no enfrentamento

entre outros tantos impactos da pandemia no futuro do trabalho. 
de doenças como o ebola, a dengue e a varíola; (iii) atuação conjunta entre os países na estratégia de combate ao vírus; (iv) adoção de medidas mais severas no início da pandemia; (v) a população africana tem sido exposta a outras cepas de COVID-19, o que condicionou seu sistema imunológico na defesa da doença; e (vi) a baixa testagem a que tem sido submetida a população (Chahad, 2020, p. 3/4).

\section{Como a pandemia da COVID-19 mudará globalmente a forma de utilização do trabalho humano?}

\subsection{Visão geral sobre a natureza das transformações em curso}

A utilização do trabalho humano será a área em que a pandemia causará seus maiores impactos, pois se trata de uma crise que afetará praticamente todos os segmentos da força de trabalho, bem como o local de trabalho diretamente. Do lado das empresas, e seu relacionamento com os trabalhadores, elas terão agir com mais flexibilidade e maior rapidez. Deverão, também, se adaptar rapidamente às mudanças, e começar imediatamente a erigir um novo conjunto de boas práticas necessárias para institucionalizar o novo modus vivendi, no contexto onde as rupturas tem uma alta probabilidade de serem mais frequentes, e persistirem por anos.

A Figura 1, extraída da publicação World Economic Forum (2020a), reúne os principais imperativos para retomar uma agenda sobre o futuro do trabalho, centralizando a discussão nos trabalhadores, nas empresas, e o comportamento e atitudes no local de trabalho. 


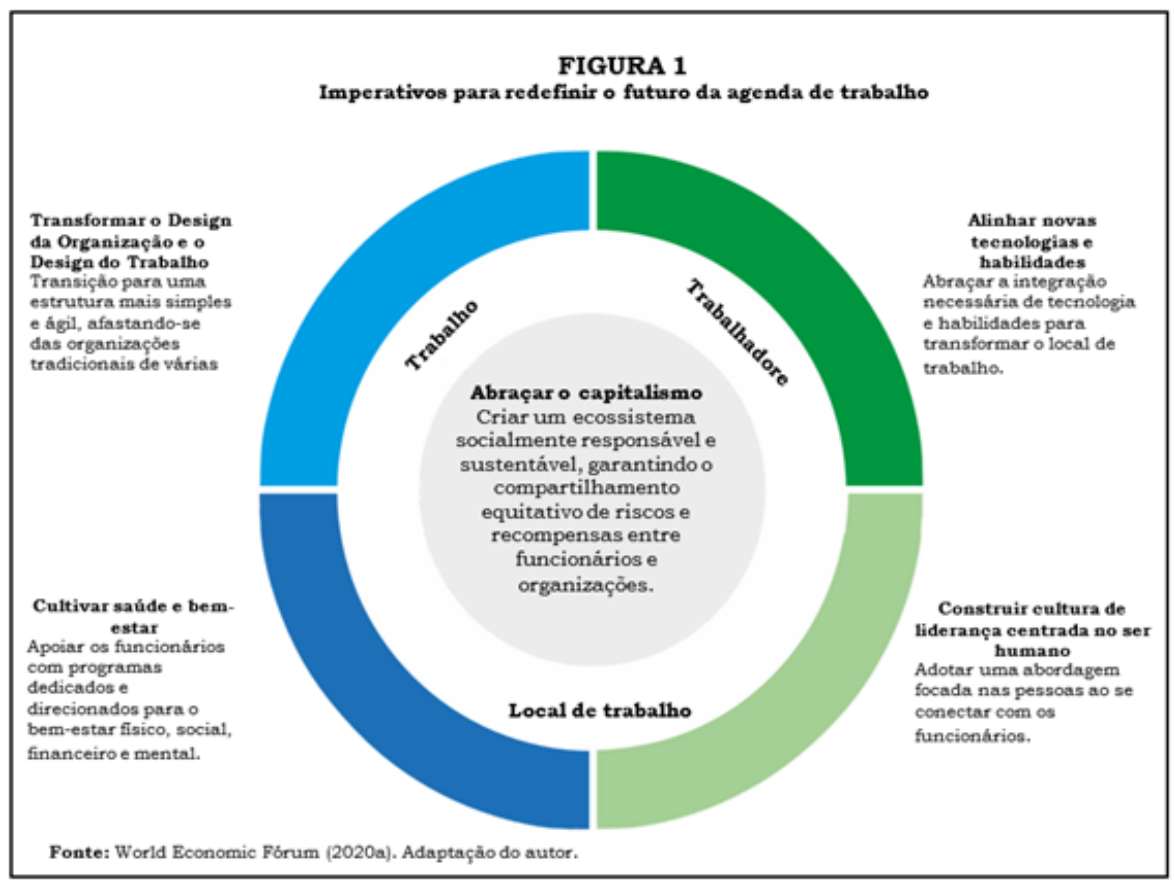

Apesar de esta figura ser autoexplicativa é interessante destacar alguns pontos. Nada prosperará sem o fortalecimento do capitalismo empreendedor, e ambientalmente sustentável, o qual assegure que riscos e recompensas possam ser distribuídos, equitativamente, entre os empregados e as organizações empresariais.

Como a pandemia é fundamentalmente uma crise com impactos imediatos e diretos sobre a força de trabalho, e o local de trabalho, ela atingirá fortemente as empresas, força motora do capitalismo, obrigando as organizações a aprenderem rápido e agir com celeridade.

Ao se adaptarem rapidamente à crise, as empresas devem começar a definir, de forma crescente, quais serão as novas boas práticas necessárias para institucionalizar as mudanças, e sacramentar quais os enfoques que adotarão para lidar com as rupturas que surgirão numa corrida tipo maratona, e não tipo sprint.

Outra forma de se observar os fatores que afetarão a natureza futura do trabalho humano, e a forma como ele deverá ser exercido, é apresentada na Figura 2 que se segue. 
Figura 2: O futuro do Trabalho depois da COVID-19: Impactos globais de longo prazo

\begin{tabular}{|l|l|}
\hline Impactos & Descrição \\
\hline $\begin{array}{l}\text { 1. A dimensão física do trabalho representa } \\
\text { trabalho, tendo como elemento principal } \\
\text { aspectos relativos a saúde e segurança. }\end{array}$ & $\begin{array}{l}\text { Estudos mostraram que os impactos se concentrarão } \\
\text { em quatro conjuntos de ocupações onde a proximidade } \\
\text { física é alta: (i) Lazer e Turismo; (ii) Varejo e } \\
\text { Hospedagem; (iii) Trabalhos de escritório com uso de } \\
\text { computação e (iv) Produção e armazenagem. }\end{array}$ \\
\hline $\begin{array}{l}\text { 2. Pandemia acelerou três tendências que } \\
\text { poderão persistir após seu término, com } \\
\text { diferentes implicações para o trabalho. }\end{array}$ & $\begin{array}{l}\text { (i) Aumento/Aceleração do Trabalho remoto hibrido } \\
\text { casa/escritório. } \\
\text { (ii) Afetam o equilíbrio entre o e-commerce e a } \\
\text { delivery economy. } \\
\text { (iii) Empresas tenderão a acelerar a automação e a } \\
\text { IA para enfrentar a COVID-19, elevando a utilização } \\
\text { permanente da robotização. }\end{array}$ \\
\hline $\begin{array}{l}\text { 3. As transições na força de trabalho poderão } \\
\text { ser em maior escala do que prevista antes } \\
\text { pandemia e o emprego na categoria de baixos } \\
\text { salários pode declinar. }\end{array}$ & $\begin{array}{l}\text { Estas tendências terão impactos mais significativos } \\
\text { em grupos mais vulneráveis como trabalhadores } \\
\text { sem estudo superior, minorias étnicas, mulheres, } \\
\text { analfabetos e jovens. }\end{array}$ \\
\hline $\begin{array}{l}\text { 4. Empresários e policy makers podem } \\
\text { acelerar inúmeros comparativos sobre o } \\
\text { futuro do trabalho que já estavam claros } \\
\text { antes da pandemia. }\end{array}$ & $\begin{array}{l}\text { As empresas têm novas oportunidades de rever como, e } \\
\text { onde, o trabalho pode ser feito. Devem privilegiar mais } \\
\text { o recrutamento baseado em qualificação e experiência } \\
\text { no trabalho, e não na graduação acadêmica. Policy } \\
\text { Makers devem priorizar o acesso equitativo à } \\
\text { infraestrutura digital, assim como novas formas de } \\
\text { facilitar a mobilidade ocupacional. }\end{array}$ \\
\hline
\end{tabular}

Fonte: MacKinsey Global Institute (2021). Elaboração do autor.

Apesar do conteúdo elucidativo, alguns comentários adicionais fortalecem a mensagem que se quer passar. Talvez a principal implicação se refira a dimensão física como um aspecto a moldar o trabalho humano.

Outra observação é que a pandemia só fez acelerar as principais tendências que já vinham ocorrendo no mercado de trabalho: maior utilização do trabalho remoto, valorização do e-commerce, aumento da automação e da utilização da inteligência artificial (IA), tópicos que serão explorados adiante.

Uma prática já consolidada será a necessidade de distanciamento físico na execução de atividades produtivas. Isto nos revela um cenário de rupturas, em curto prazo, durante a pandemia da COVID-19. A previsão é que neste, e em outras áreas, esses efeitos de distanciamento físico tenderão a ser duradouros.

A importância que o distanciamento físico exercerá no local de trabalho pode ser assim resumida:

"COVID-19 elevated some elements often overlooked in work: the physical to one another and to costumers, the level of human interactions required, and the physical environment in which work takes place. Physical space and how employees do their 
jobs whiten it came into sharp focus as companies considered how best to ensure the health and safety of the workforce and customers in the early days of pandemic. Occupations that requires more human interactions, physical proximity, and on-site the most disruption during the pandemic... and these factors also may partly determine changes in how and where work is done after the pandemic recedes" (Mckinsy Global Institute, 2021, p. 23).

Outro fato observável é que, ao se forçar as empresas, e os consumidores a se adaptarem rapidamente à necessidade de menos inteirações humanas, e menor contato físico, a COVID-19 afetará duas tendências em adição ao trabalho online, as quais terão efeitos duradouros sobre o futuro do trabalho: a utilização de ferramentas e tecnologias digitais nas transações, aconselhamento e cooperação; e a adoção, em larga escala, da digitalização, automação e inteligência artificial, nos locais de trabalho. Um resultado desta última tendência é que haverá um grande aumento da utilização de robôs em todas as atividades econômicas, bem como nos locais de trabalho.

A publicação The Future of Jobs Report (World Economic Forum, 2020b) apresenta outras tendências que moldarão o futuro do trabalho durante, e após a pandemia. Entre elas destacam-se: (a) a ritmo da adoção de novas tecnologias permanecerá forte e irá se acelerar em algumas áreas devido à COVID-19; (b) a automação simultaneamente com a recessão provocada pela pandemia da COVID-19, está criando um duplo cenário de rupturas para os trabalhadores; e (c) na ausência de esforços proativos a desigualdade será, provavelmente, exacerbada pelo duplo impacto decorrente do avanço tecnológico e da recessão pandêmica:

Para esta Instituição:

"The COVID-19 appears to be deepening existent inequalities across labour markets, to have reversed the gain in employment made since the Global Financial Crisis in 2007-2008, and to have accelerated the arrival of the future of work. The changes heralded by the COVID-19 pandemic have compounded the long-term changes already triggered by the Fourth Industrial Revolution which has, consequently, increased in velocity and depth" (World Economic Forum, 2020b, p. 9).

\subsection{O planejamento dos negócios em resposta à pandemia}

A pandemia ainda está em curso a nível mundial, mas é certo que o ambiente de negócios mudará significativamente. As empresas passarão, maciçamente, a privilegiar o trabalho remoto no planejamento de suas atividades, mesmo sabendo que se defrontarão com problemas legais enquanto um novo marco jurídico não for erigido. Por outro lado, elas se afastarão, paulatinamente, de adaptações pós-pandemia que 
envolva a utilização de força de trabalho.

A Figura 3 contém as principais ações que as empresas pretendem tomar durante, e após a COVID-19. Acelerar a digitalização e fornecer maiores oportunidades de trabalho remoto aos seus colaboradores despontam, amplamente, como principais componentes do planejamento estratégico das organizações. Já o aumento na utilização da força de trabalho desfruta de pouco interesse das empresas.

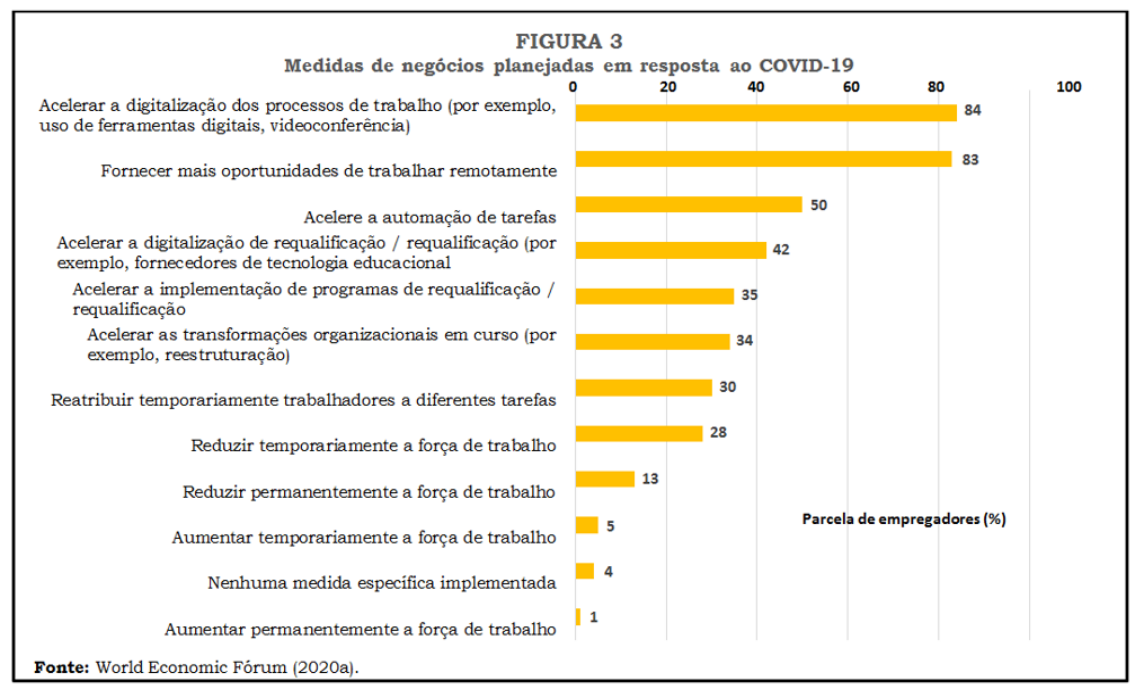

Outra transformação no comportamento das empresas decorrente da COVID-19 tem sido, como já mencionada, sua atitude com relação ao trabalho remoto. Antes da pandemia esta forma de trabalho era um conceito distante, tanto para as empresas, quanto para os trabalhadores.

A pandemia modificou drasticamente este cenário. Antes de seu surgimento a grande maioria das empresas ofereciam menos $25,0 \%$ de oportunidades de utilização do trabalho remoto. Somente uma minoria de estabelecimentos oferecia um alto percentual (mais de 75,0\%) de oportunidades de trabalho remoto, conforme a Figura 4 nos revela. 


\section{FIGURA 4}

Impacto do COVID-19 nas práticas de trabalho remoto

\begin{tabular}{|c|c|c|c|c|c|c|c|c|c|c|c|}
\hline \multicolumn{7}{|c|}{ Antes da pandemia COVID-19: } & $60 \%$ & $70 \%$ & $80 \%$ & $90 \%$ & $100 \%$ \\
\hline Menos de $25 \%$ & $85.99 \%$ & & & & & & & & & & \\
\hline $25 \%$ a $49 \%$ & $7.96 \%$ & & & & & & & & & & \\
\hline $50 \%$ a $75 \%$ & $3.33 \%$ & & & & & & & & & & \\
\hline mais de $75 \%$ & $2.73 \%$ & & & & & & & & & & \\
\hline \multicolumn{12}{|c|}{ Atualmente / durante a pandemia COVID-19: } \\
\hline & \multicolumn{2}{|c|}{$0 \%$} & $20 \%$ & $30 \%$ & $40 \%$ & \multirow[t]{4}{*}{$50 \%$} & \multirow[t]{4}{*}{$60 \%$} & \multirow[t]{6}{*}{$70 \%$} & \multirow[t]{6}{*}{$80 \%$} & \multirow[t]{6}{*}{$90 \%$} & \multirow[t]{6}{*}{$100 \%$} \\
\hline Menos de $25 \%$ & $12.52 \%$ & & & & & & & & & & \\
\hline $25 \%$ a $49 \%$ & $21.69 \%$ & & & & & & & & & & \\
\hline $50 \%$ a $75 \%$ & $18.12 \%$ & & & & & & & & & & \\
\hline mais de $75 \%$ & $47.68 \%$ & & & & & \multirow{7}{*}{$50 \%$} & \multirow{7}{*}{$60 \%$} & & & & \\
\hline \multicolumn{6}{|c|}{$\begin{array}{l}\text { Estado futuro antecipado, uma vez que os regulamentos sejam } \\
\text { suspensos: }\end{array}$} & & & & & & \\
\hline & & $10 \%$ & $20 \%$ & $30 \%$ & $40 \%$ & & & \multirow[t]{5}{*}{$70 \%$} & \multirow[t]{5}{*}{$80 \%$} & \multirow[t]{5}{*}{$90 \%$} & \multirow[t]{5}{*}{$100 \%$} \\
\hline Menos de $25 \%$ & $37.8 \%$ & & & & & & & & & & \\
\hline $25 \%$ a $49 \%$ & $38.64 \%$ & & & & & & & & & & \\
\hline $50 \%$ a $75 \%$ & $19.02 \%$ & & & & & & & & & & \\
\hline mais de $75 \%$ & $4.55 \%$ & & & & & & & & & & \\
\hline
\end{tabular}

No mundo pandêmico tem ocorrido uma mudança significativa na oferta de possibilidades de utilização do trabalho remoto. Agora a grande maioria das empresas pesquisadas está planejando oferecer mais oportunidades de trabalho remoto.

\subsection{Alterações no perfil da demanda de trabalho durante e após a COVID-19}

Uma tendência que já vinha se desenhando era alteração na estrutura setorial das ocupações. A Figura 5 nos revela a mudança na demanda de trabalho que já vinha ocorrendo no caso americano, e que deverá ganhar mais força pós-pandemia, disseminando-se por outros países.

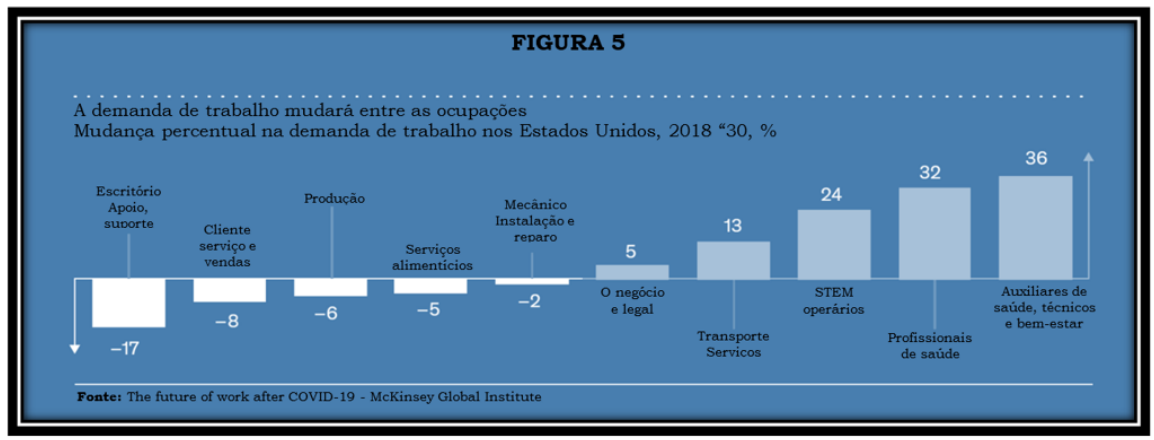


De fato, a figura mostra a mudança do eixo setorial na demanda com um forte declínio nas ocupações voltadas para trabalho em escritórios e atividades correlatas, e um grande aumento das necessidades de ocupações em setores da área da saúde.

Essas alterações na demanda setorial decorrem de três fatos já mencionados: (i) as mudanças no trabalho remoto e suas inteirações virtuais; (ii) o maior uso do e-commerce e de outras plataformas digitais; e (iii) os desdobramentos sobre o trabalho decorrentes da automação e da IA.

"In each case, the pandemic pushed companies and consumers to rapidly adopt new behaviours. We consequently see a sharp discontinuity between the level of adoption before and during the pandemic. The extent to which trends persist after the pandemic remain to be seen, but there is growing evidence that many of new behaviours will persist, even if at somewhat lower levels than the peak." (Mckinsy Global Institute, 2021, p. 6).

A Figura 6, que se segue, oferece uma ilustração da prevalência dessas tendências antes, durante e depois da pandemia da COVID-19. 


\section{FIGURA 6}

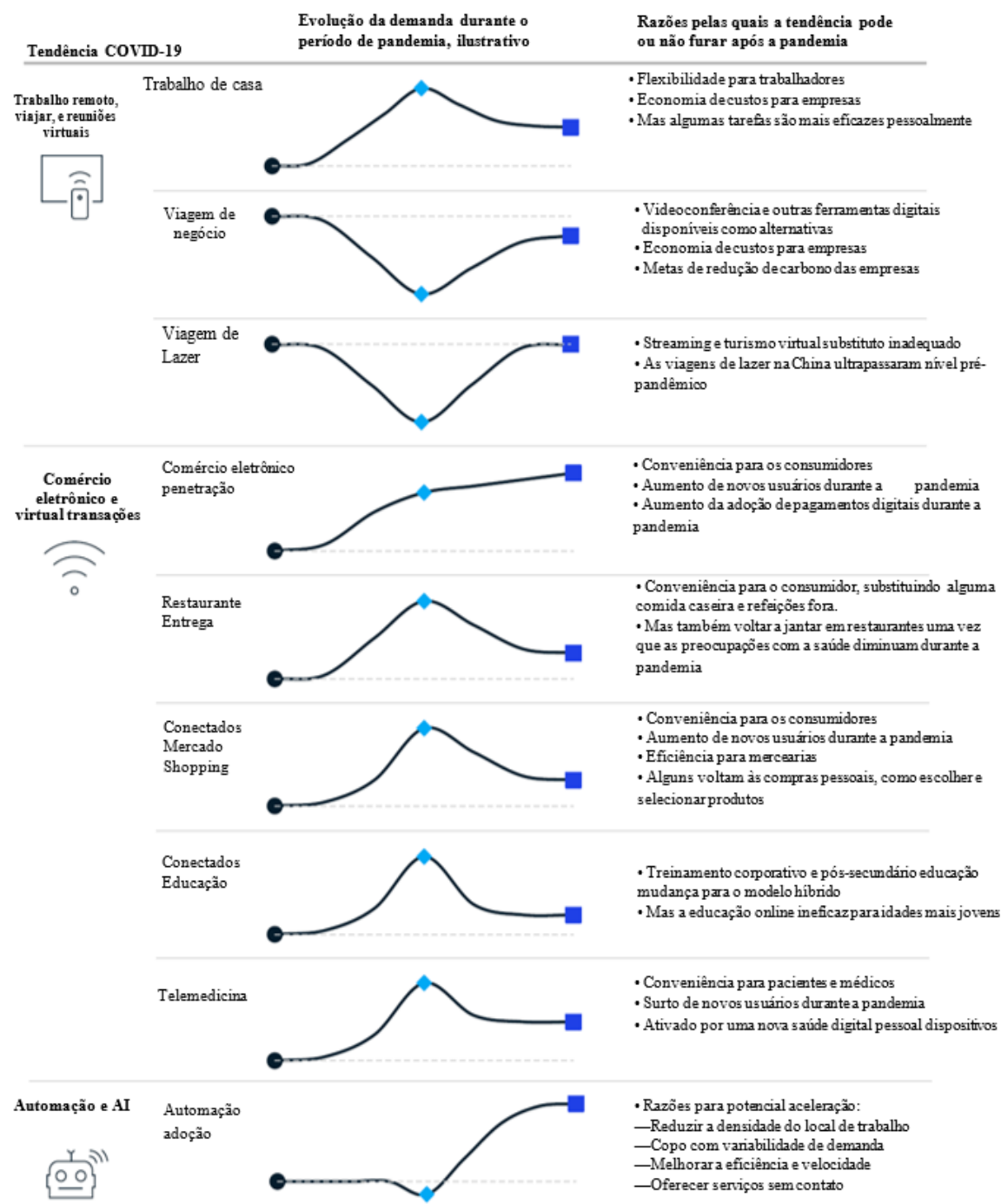

Fonte: McKinsey Globalinstitute (2021).

Com relação ao trabalho remoto tem havido, e isto persistirá, mas em menor intensidade, um aumento do trabalho domiciliar. Já viagens de negócios e de lazer têm sofrido forte queda, e sua recuperação pós-pandêmica não fará retornar, 
provavelmente, aos níveis anteriores. Já o comércio eletrônico, e a automação, continuarão crescendo fortemente pós-pandemia, enquanto setores como entregas de restaurantes e telemedicina, por exemplo, se elevarão inicialmente para caírem após o pico da pandemia, mas se estabilizarão em níveis maiores que na fase anterior à COVID-19.

\section{Trabalho remoto, home office e teletrabalho ${ }^{3}$}

\subsection{A percepção dos agentes econômicos}

A abrangência dos impactos do Coronavírus sobre o mundo do trabalho é enorme, seja se observando o curto prazo, ou longo prazo, sendo impossível exaurir estes impactos. Há, contudo, um predomínio na literatura recente, dos principais impactos detectados posteriormente ao início da pandemia.

Certamente o impacto mais perceptível da COVID-19 sobre a força de trabalho tem sido o dramático aumento de empregados trabalhando remotamente. Conforme nos mostrou a seção 2.1, esta é uma tendência que veio para ficar. Embora o teletrabalho, e outras formas de trabalho remoto, vinham sendo utilizadas a longo do tempo, com a chegada da pandemia ele cresceu rapidamente, em decorrência dos desdobramentos trazidos pelas novas soluções digitais como, por exemplo, instrumentos de vídeo conferências, possibilidade de compartilhamento de documentação, e expansão da capacidade da computação pelo sistema de "nuvem".

Sob a ótica das empresas, a adoção do trabalho remoto possibilitou que elas continuassem operando, e garantissem, de forma rápida, a saúde e a segurança dos empregados, ainda que de forma embrionária. Mas, sob a ótica dos trabalhadores, e de sua vida familiar, o impacto dessa nova forma de trabalhar trouxe algumas vantagens, mas muitos problemas, pois as linhas entre tempo de trabalho e o tempo da vida familiar ficaram embaralhadas.

Esta nova situação para os trabalhadores aparece bem descrita na frase abaixo:

"Among some workers, COVID-19 will be forever remembered as the virus that turned their homes into office spaces. When the pandemic started, employees working remotely even part time were few and limited largely to advanced Western economies. Working from home was primarily something done when a child was sick or a household repair person was at work....

3 Com o advento da pandemia da COVID-19 acelerou-se a utilização em larga escala do trabalho remoto. Este é um rótulo genérico para diversos tipos de trabalhos realizados de forma online. Dois se destacam: teletrabalho e home office. Considera-se teletrabalho a prestação de serviços preponderantemente fora das dependências do empregador, ou seja, escritório, loja, ou outro local físico, com o uso de tecnologias de informação e comunicações que, por sua natureza, não se constituem como trabalho externo. Por outro lado, o home office constitui modalidade de trabalho à distância, executada no domicílio do empregado, de forma eventual, e utilizando tecnologias de informação e comunicação. Isto, porém, não o impede de efetuar tarefas em outros locais de trabalho. Existe, ainda, dois outros tipos de trabalho remoto. O trabalho móvel, quando não há um lugar fixo, de forma que o trabalho pode ser realizado em qualquer localidade, e o trabalho em telecentro, quando o empregado, em lugar de ir à sede da empresa, se dirige a um escritório compartilhado. 
legions of workers cleared off their kitchen counters and dining room tables to make room for laptops, screens, and key boards, while their employers scrambled to deploy digital tools to help them maintain the productivity they had in the office (Mckinsey Global Institute, 2021, p. 37).

Nesse sentido, alguns especialistas veem com ceticismo o futuro do trabalho remoto, como representando um avanço no mercado de trabalho causado pela pandemia. Para eles haverá um tempo em que as pessoas darão conta de que o trabalho remoto, em todas suas formas, nada tem a ver com o "paraíso" com que sonhavam, onde haveria uma fácil conciliação entre a vida pessoal, a familiar e a profissional. Ou seja, o trabalho à distância traz novas pressões, pode levar a um novo tipo de isolamento, assim como dificulta, significativamente, a comunicação entre colegas e equipes. A dimensão social do trabalho (socialização) poderá ficar comprometida.

Para outros, porém, esta transformação decorrente do home office, com todas suas mazelas, veio para ficar. Esta tendência, que já vinha se esboçando antes da pandemia, encontrou nessa um poderoso acelerador para sua consolidação. Essa nova realidade fez sucesso num grande contingente de trabalhadores, além de oferecer ao setor empresarial um tutorial sobre as limitações e os benefícios do trabalho remoto.

O vírus fez superar muitas barreiras tecnológicas e culturais que freavam o deslanche do trabalho remoto no passado, provocando uma drástica mudança estrutural sobre o local onde a atividade de trabalho deve ocorrer, pelo menos para uma parcela de indivíduos engajados no mercado de trabalho.

De qualquer forma, há uma clara percepção de que a execução de trabalho remoto abrange uma fatia limitada da força de trabalho. O mencionado relatório do Mckinsey Global Institute realizou um amplo estudo procurando detectar onde o trabalho remoto pode ser realizado, e com chance de prosperar. Dentre suas principais conclusões merecem destaque as seguintes:

1. São as ações, as tarefas e as atividades, e não as ocupações, que determinam o potencial para a utilização do trabalho remoto;

2. Este potencial depende do mix de atividades desenvolvidas em cada ocupação, e seu contexto espacial, físico e interpessoal. Isto depende se o trabalhador necessita estar presente fisicamente para realizar as tarefas; se é preciso interagir com outros membros da equipe; ou se precisa utilizar máquinas e equipamentos que estão alocadas no espaço físico de trabalho;

3. A pandemia mostrou que se, uma atividade possa ser realizada remotamente, ela é mais bem desempenhada ao ser feita pessoalmente no local físico da empresa. Alguns exemplos são: negociar e tomar decisões críticas, realizar ensinamentos e treinamentos; solucionar problemas que envolvem criatividade e pessoalidade, e desenvolver bons relacionamentos com colegas e clientes, entre outros; e 
4. Dentre estas atividades a mais emblemática seja, talvez, a atividade "educacional". Teoricamente ela pode ser realizada remotamente, mas parece ser mais efetiva quando realizada de modo presencial. Uma observação recorrente entre os principais envolvidos, pais, professores e alunos é que a qualidade da educação sofreu uma queda durante a fase de isolamento social provocada pela pandemia, sendo isto mais grave entre as crianças e alunos portadores de necessidade especiais.

\subsection{O alcance do trabalho remoto - a ótica setorial}

Muito embora a penetração do trabalho seja um fato consumado, bem como representa uma nova realidade que veio para ficar, seu alcance entre setores é bastante desigual, conforme nos revela a Figura 7. Ela foi obtida a partir de uma enquete entre trabalhadores que tiveram que responder à seguinte pergunta: "to what extent can your work be done from home?" (Blundell e Machin, 2020, p. 7).

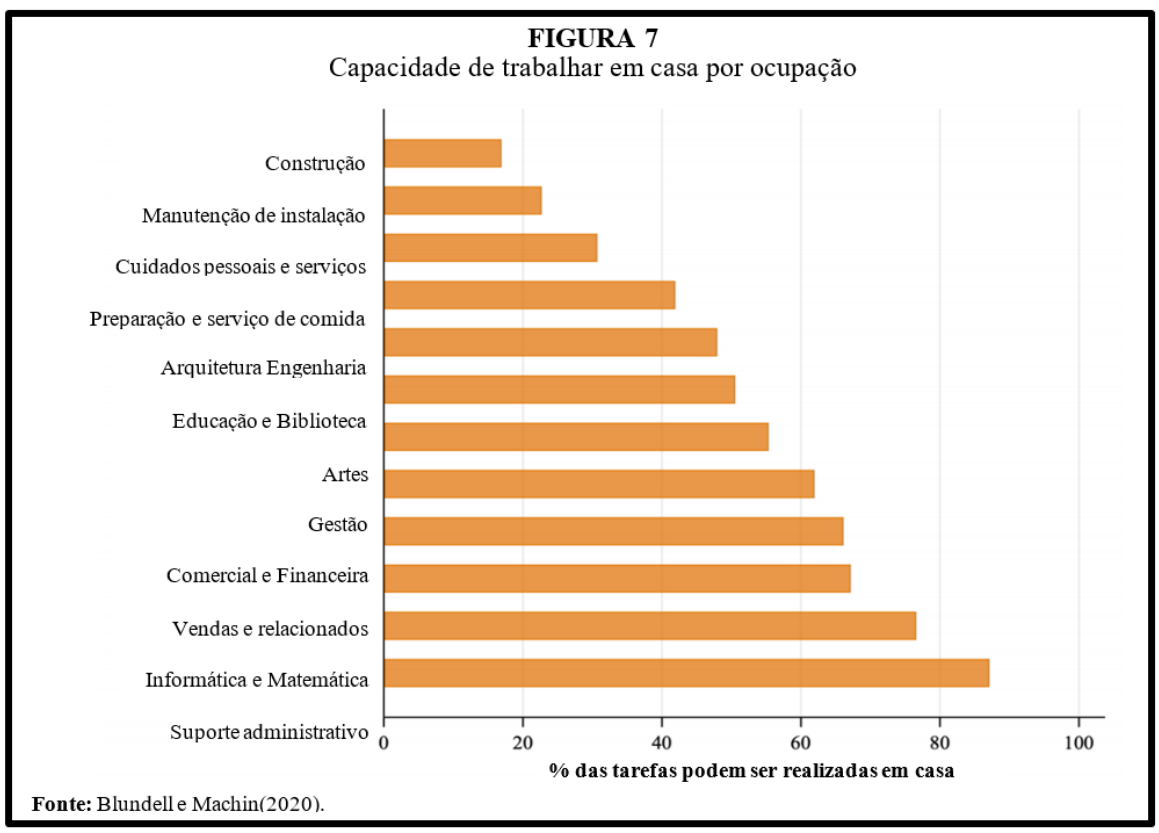

Nota-se que existe uma variação muito grande, entre setores, na extensão em que o trabalho remoto pode ser realizado, a partir do domicilio do trabalhador. Enquanto trabalhadores na indústria de construção afirmaram que somente $17,0 \%$ de suas tarefas poderiam ser realizadas a partir de casa, esta cifra é de 87,0\% nos serviços de escritórios e nos trabalhos administrativos. 
A principal implicação deste diferencial de possibilidades de execução das tarefas, a partir da residência do trabalhador, será o de promover uma desigualdade de renda, na medida em que o trabalho remoto será cada vez mais valorizado. Aqueles engajados em setores e ocupações com dificuldades de serem realizadas remotamente deverão ser menos valorizados, auferindo, provavelmente, menores rendimentos.

\subsection{Vantagens e desvantagens do trabalho remoto}

Apesar de haver um amplo consenso de que o trabalho remoto, que já era uma tendência antes da pandemia, deverá permanecer, e se ampliar após ela, um balanço entre as vantagens e desvantagens aponta uma ligeira prevalência desta última, conforme mostra a Figura 8.

\begin{tabular}{|c|c|}
\hline \multicolumn{2}{|c|}{ Figura 8: O Alcance do trabalho remoto durante e após a pandemia } \\
\hline Vantagens destacadas & Desvantagens destacadas \\
\hline $\begin{array}{l}\text { - Melhoria na produtividade; } \\
\text { - Reuniões com mais foco; } \\
\text { - Mais tempo com a família; } \\
\text { - Mais tempo livre (sem o deslocamento para o } \\
\text { trabalho); e } \\
\text { - Redução de custos para a empresa (aluguel e etc) e } \\
\text { para o funcionário (alimentação e transporte). } \\
\text { - Perda de concentração por causa da família e das } \\
\text { tarefas do lar; } \\
\text { - Falta de infraestrutura (scanner, impressora e etc); } \\
\text { - Perda da noção do todo (presencialmente é mais } \\
\text { fácil entender o que está acontecendo; e reforçar o } \\
\text { alinhamento de objetivos é fundamental); } \\
\text { - Sensação de trabalho onipresente, sem hora para } \\
\text { acabar; } \\
\text { - Menos participação de algumas pessoas em } \\
\text { reuniões (algumas não ligam a câmera e só ouvem); e } \\
\text { - É preciso ser mais ativo, mais empreendedor, caso } \\
\text { contrário as coisas não andam. }\end{array}$ & $\begin{array}{l}\text { - Falta de contato pessoal com os colegas de } \\
\text { trabalho; } \\
\text { - Perda de concentração por causa da família e } \\
\text { das tarefas do lar; } \\
\text { - Falta de infraestrutura (scanner, impressora } \\
\text { e etc); } \\
\text { - Perda da noção do todo (presencialmente é } \\
\text { mais fácil entender o que está acontecendo; } \\
\text { e reforçar o alinhamento de objetivos é } \\
\text { fundamental); } \\
\text { - Sensação de trabalho onipresente, sem hora } \\
\text { para acabar; } \\
\text { - Menos participação de algumas pessoas em } \\
\text { reuniões (algumas não ligam a câmera e só } \\
\text { ouvem); e } \\
\text { - É preciso ser mais ativo, mais empreendedor, } \\
\text { caso contrário as coisas não andam. }\end{array}$ \\
\hline
\end{tabular}

Fonte: Miceli et alli (2020). Elaboração do autor.

Dentre as vantagens aparecem os ganhos com o tempo de transporte. Certamente este é mais destacado benefício nos médios e grandes centros urbanos, sempre sujeitos a grandes congestionamentos. Para a grande massa de trabalhadores, e moradores em áreas mais afastadas do centro, experimentando muitas horas desperdiçadas no deslocamento, o trabalho remoto tem promovido um desejado ganho de horas de lazer e tempo para dispender com a família. Além disso, a redução dos gastos com transporte, proporcionará mais tempo livre para atividades físicas,com consequências positivas para a melhoria da saúde do individuo. 
Outra vantagem que merece destaque, diz respeito ao fato de que o trabalho remoto proporciona mais flexibilidade nos horários de trabalho, sendo muito valorizado como requisito na busca por uma vaga de emprego. Este requisito tem sido apontado como uma nova moeda de negociação na fase de recrutamento de profissionais, bem como se mostrado útil para elevar a rentabilidade das empresas e, também, no recrutamento dos melhores talentos.

Dentre as desvantagens do trabalho remoto despontam três: (i) falta de espaço adequado para conciliar vida profissional e vida familiar; (ii) falta de infraestrutura para o exercício do trabalho; e (iii) perda de foco.

Os escritórios são aparelhados para o pleno desempenho da atividade de trabalho. Já o exercício desta atividade no domicilio trouxe dificuldades, pois as famílias tiveram que se adaptar até mesmo em seus aposentos (quarto, sala, e espaço de lazer) para permitir a utilização do computador e outras informáticas. Este improviso foi desenhado sem qualquer preocupação com aspectos sanitários, de segurança ou mesmo bem-estar dos trabalhadores dentro do domicílio.

Com relação à vida familiar, os desafios têm sido ainda maiores, pois envolve o elemento humano, com destaque para o cuidado com os filhos na fase de isolamento social. Os pais tiveram que mudar rotinas, horários e espaços para dar suporte às aulas online, e ainda dar total atenção aos filhos praticamente 24 horas por dia. Até mesmo os computadores precisaram ser divididos entre pais e filhos. No caso da mãe-trabalhadora o quadro tem sido ainda mais dramático.

Adiciona-se, também, que o home office traz externalidades negativas decorrente do compartilhamento do mesmo espaço para trabalhar e o convívio em vida familiar. Tornou-se uma constante os participantes de eventos online ouvirem gritos, choro, correrias, portas batendo, ou crianças chamando em altos brados, aspectos de difícil controle na fase embrionária da utilização do trabalho em casa com maior frequência.

Por fim, temos a desvantagem da perda de foco assim definida pela MIT Technology Review:

"No cenário comum dos escritórios das empresas, com uma divisão clara entre casa e trabalho, os trabalhadores estavam acostumados a ver suas casas como um espaço de descanso e lazer. Quando este mesmo ambiente passa a incluir também o trabalho, fica mais difícil fazer a separação e manter o foco durante o horário de expediente. No cenário da pandemia, considerando que muitos destes trabalhadores ainda têm que lidar com filhos em casa, fica mais difícil ainda achar essa concentração nas atividades de trabalho". (Miceli, A.L. et alli, 2020, p. 41) 


\subsection{Os impactos psicológicos decorrentes do home office}

A grande consequência dessa dupla militância entre trabalho e vida familiar dentro do mesmo recinto tem sido o aparecimento de tensões e pressões entre os trabalhadores. Como vimos é difícil conciliar crianças subindo em você, cachorros latindo, aspirador de pó em operação e ter um bom desempenho no trabalho. Isto gera muita ansiedade e cansaço. A Figura 9 traz uma síntese dos principais sintomas psicológicos, emocionais, mentais e físicos que tem sido detectados pela pratica do home office.

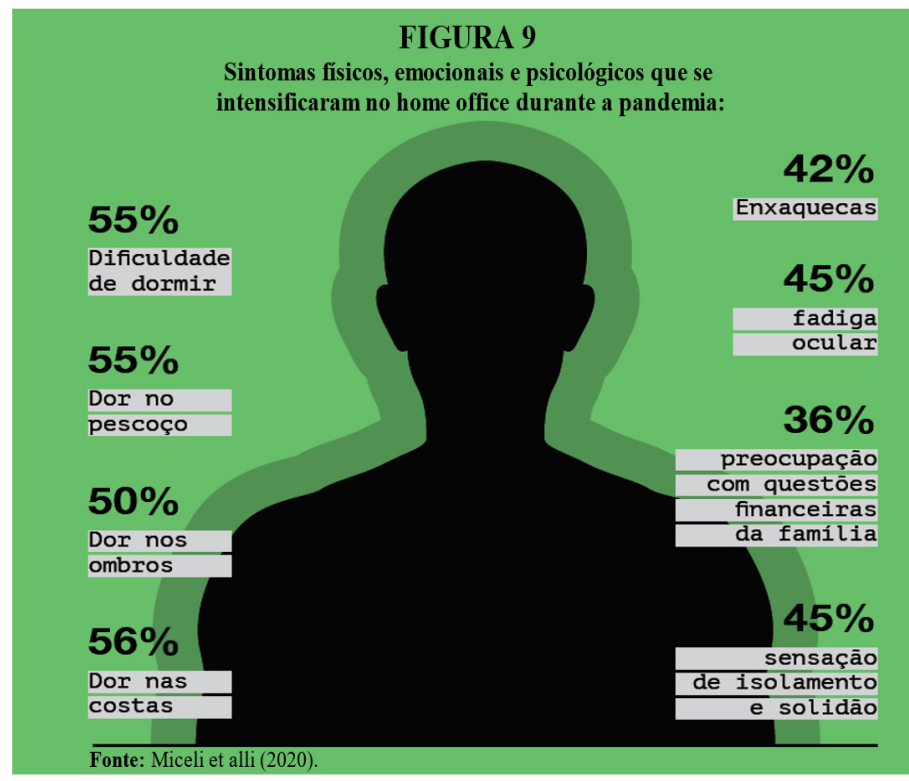

Além disso, outras dificuldades que surgem são um aumento do stress emocional, a elevação dos riscos à saúde mental, bem como uma debilitação da saúde física, todos representando fatores que se potencializam.

\subsection{As expectativas sobre o futuro do trabalho remoto após a pandemia}

Como será o futuro do trabalho remoto após a pandemia? Mesmo com ela ainda em andamento, o mundo dos negócios já vai ensaiando um retorno às atividades presenciais. As empresas já estão preparando o retorno presencial de parcela de seus empregados às fabricas e aos escritórios. Essa reabertura dos locais de trabalho, bem como da economia em geral, não será, contudo, estática. Além disso, existe o revés causado pelas novas ondas da pandemia, indicando que este retorno não ocorrerá da 
noite para o dia. É quase certo que o controle do vírus levará muito tempo, e persistirá, longamente, em sua forma endêmica.

De acordo com o ILO (2020, p. 27):

"Governments and social partners will have to plan for several scenarios, in which restrictions will be increased or eased according to epidemic is advancing or receding on their territory and prepare for teleworking arrangements to once again become generalized on short notice. During the next, highly uncertain period, workers, employers, and governments will have to adapt to the new way of living and working, which will require new behaviors and new norms. It most likely will evolve a hybrid or blended form of isolation (i.e., teleworking) and deconfinement (i.e., the possibility to use the workplace but with controlled conditions based on physical distancing)."

Mesmo diante de tantas incertezas, a própria Instituição procura estimular a crescente adoção do trabalho remoto, em todas suas categorias. Para isso tem feito inúmeras recomendações para que esta forma de trabalhar seja uma importante resposta à pandemia da COVID-19.

A Figura 10, que se segue, revela aquilo que tem sido chamado de um conjunto de "boas práticas" empresariais visando tornar o trabalho remoto mais eficaz. Estas práticas contemplam, entre outras, um forte suporte gerencial das empresas, a utilização de ferramentas e treinamentos apropriados, que haja expectativas claras entre as partes intervenientes e, sobretudo, uma forte dose de confiança mútua. 
Figura 10: OIT- as boas práticas para tornar o trabalho remoto mais eficaz

\begin{tabular}{|c|c|}
\hline Item & Descritivo \\
\hline $\begin{array}{l}\text { 1. Apoio de } \\
\text { gerenciamento }\end{array}$ & $\begin{array}{l}\text { Da alta gerência às (aos) supervisoras (es) de linha de frente. Pesquisas } \\
\text { mostram que a resistência de gerentes ao teletrabalho é um grande } \\
\text { obstáculo para que essa prática seja eficaz. Gerenciar quem trabalha } \\
\text { remotamente de maneira eficaz exige uma abordagem de gerenciamento } \\
\text { baseada em resultados. Isso requer definir metas, objetivos e tarefas e, } \\
\text { em seguida, monitorar e discutir o progresso, sem impor a apresentação } \\
\text { em excesso de relatórios. Como muitas escolas e creches estão fechadas } \\
\text { nesse momento, talvez seja necessário fazer alguns ajustes nas metas de } \\
\text { desempenho de trabalhadoras(es) com responsabilidades de cuidar de } \\
\text { outras pessoas. }\end{array}$ \\
\hline $\begin{array}{l}\text { 2. Ferramentas } \\
\text { e treinamento } \\
\text { apropriados }\end{array}$ & $\begin{array}{l}\text { Isso inclui ter acesso a equipamento adequado, laptop, aplicativos } \\
\text { de teletrabalho, suficiente assistência técnica e treinamento para } \\
\text { gerentes e trabalhadoras (es) remotos. Dado o risco real de isolamento } \\
\text { social associado ao teletrabalho em tempo integral, todos os esforços } \\
\text { devem empreendidos para manter a(o) profissional em contato com } \\
\text { supervisoras(es), colegas e a instituição como um todo. }\end{array}$ \\
\hline 3. Expectativas claras & $\begin{array}{l}\text { Todas as partes precisam saber o que é esperado daquelas pessoas que } \\
\text { trabalham em casa, suas condições de emprego, horários em que podem ser } \\
\text { contatas e como monitorar progresso e relatar os resultados. Por exemplo, é } \\
\text { essencial estabelecer regras básicas claras sobre quando as(os) funcionárias(os) } \\
\text { precisam ou não estar disponíveis para trabalhar; e respeitá-las. }\end{array}$ \\
\hline $\begin{array}{l}\text { 4. Ser capaz de controlar } \\
\text { o seu tempo }\end{array}$ & $\begin{array}{l}\text { O teletrabalho pode oferecer às (aos) trabalhadoras (es) flexibilidade } \\
\text { para realizar suas tarefas no momento e no local que melhor lhes convier, } \\
\text { desde que permaneçam disponíveis durante o horário normal de trabalho } \\
\text { da instituição. Essa flexibilidade é essencial para que o teletrabalho seja } \\
\text { eficaz, pois permite que quem trabalha remotamente organize seu trabalho } \\
\text { remunerado de acordo com suas responsabilidades pessoais, como cuidar } \\
\text { de crianças, pais idosos ou parentes doentes. }\end{array}$ \\
\hline $\begin{array}{l}\text { 5. Uma estratégia } \\
\text { pessoal para trabalhar } \\
\text { melhor }\end{array}$ & $\begin{array}{l}\text { Mesmo que as expectativas estejam claras, ainda é essencial que as pessoas } \\
\text { em sistema de teletrabalho criem suas próprias estratégias pessoais para } \\
\text { um gerenciamento eficaz da fronteira entre o trabalho remunerado e a } \\
\text { vida pessoal. Isso inclui a delimitação de um espaço de trabalho silencioso } \\
\text { e a possibilidade de se desconectar em horários específicos reservados ao } \\
\text { descanso e à vida pessoal. }\end{array}$ \\
\hline 6. Confiança & $\begin{array}{l}\text { A "cola" que mantém tudo isso junto. Gerentes, teletrabalhadoras (es) e } \\
\text { colegas precisam confiar uns nos outros. Sem isso, o teletrabalho não é eficaz. }\end{array}$ \\
\hline
\end{tabular}

Fonte: OIT Brasil (2020). Elaboração do autor.

No campo das expectativas futuras sobre o teletrabalho, exacerbado pela COVID-19, existem argumentos baseados em estudos estatísticos (Brussevich, DablaNorris e Khalid, 2020), de que sua maior utilização pode ampliar a desigualdade intergeracional de renda dos trabalhadores. 
Com base num conceito denominado índice de teletrabalho (tele trabalhibilidade), eles avaliaram a capacidade dos indivíduos trabalharem remotamente, segundo a idade e a educação conjuntamente. Os resultados se encontram na Figura 11 apresentada a seguir.

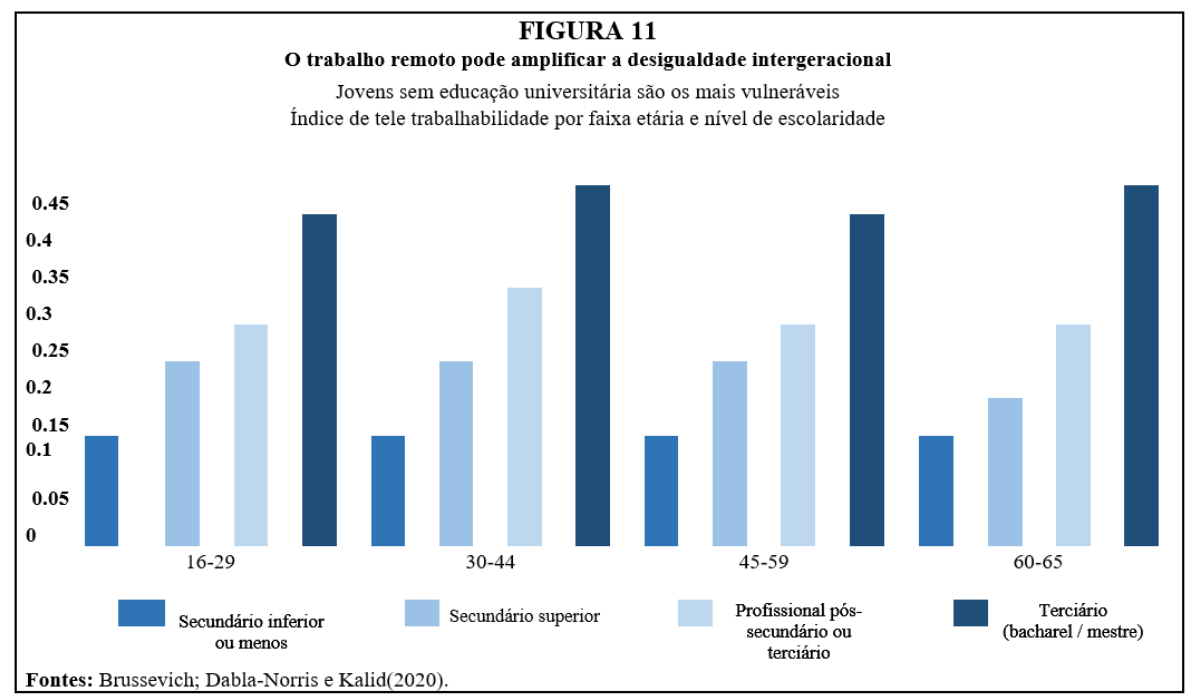

Eles encontraram, na média, que ter escolaridade universitária melhora muito a probabilidade de trabalhar remotamente entre todos os grupos etários. Do mesmo modo, os trabalhadores mais velhos com baixo nível de escolaridade ainda possuem um alto índice de teletrabalho, refletindo os efeitos do ciclo de vida, uma vez que há uma progressão natural para ocupações mais seniores ao longo da carreira do trabalhador.

Estes resultados sugerem que os ganhos de renda e gaps de renda entre gerações que já haviam sido exacerbados pela crise financeira global, podem se ampliar ainda mais devido à pandemia, penalizando trabalhadores jovens menos educados.

\section{A COVID-19 acelerou os processos de automação e digitalização}

\subsection{Os processos de automação}

Ao forçar os trabalhadores, consumidores e empresários a se adaptarem rapidamente à necessidade de menos contato físico, bem como inteirações humanas, a COVID-19 afetou duas tendências, em adição à disseminação do trabalho remoto, com efeitos duradores sobre a força de trabalho: (i) a utilização de ferramentas digitais para consultoria, transações e colaboração e (ii) a adoção da automação, da inteligência artificial, e da robótica nos locais de trabalho, conforme já mencionado. 
Especificamente com relação ao avanço da inteligência artificial, Smith e Smith (2020, p. 1) qualificam da seguinte forma sua relação com a pandemia:

\begin{abstract}
"We are here to suggest there is a new AI among us now. 'AI' is not an acronym for 'artificial intelligence', but 'AI' now could be an acronym for 'An Infection". It's not news to say that coronavírus is having a huge impact on the world of world. As we bring these words together, it's worth a step back to understand that perhaps this virus marks the beginning of the Forth Industrial Revolution, the age of AI, and that we are at the beginning of a new normal."
\end{abstract}

A necessidade de amplas inteirações buscando reduzir o contato físico entre as pessoas acabam tendo efeitos perversos sobre a economia. Algumas estimativas disponíveis mostram que $1 / 4$ dos empregos no mercado de trabalho requerem interações físicas e, desta forma, são diretamente afetados pela pandemia. O exemplo mais latente disso ocorre no setor de saúde, onde enfermeiros, médicos e pacientes estão, frequentemente, em contato entre si, elevando drasticamente o risco de contraírem a doença (Korinek e Stiglitz, 2021).

Sob a ótica econômica, os impactos da COVID-19, em decorrência da necessidade de reduzir o contato entre pessoas, podem ser entendidos sobre a ótica dos custos econômicos:

\begin{abstract}
"In economic language, covid-19 has added a 'shadow cost' on labour that requires proximity. This shadow cost reflects the dollar equivalent of all the costs associated with the increase risk of disease transmission, including the costs of the adaptations required for covid-19. It consists of losses of both quality adjusted life days from increased morbidity and quality adjusted life years from increased mortality, as well as the cost of measures to reduce these risks, such as extra protective equipment and distancing measures for workers." (Korinek e Stiglitz, 2021, p. 1)
\end{abstract}

Estes custos adicionais acabam por acelerar o desenvolvimento de novas tecnologias para automatizar o trabalho humano. Esta automatização não está sujeita a contrair doenças, especialmente em época de pandemia como hoje vivemos.

A própria mudança para o trabalho remoto passou a exigir mais automatização e digitalização no seu fluxo de trabalho. Mesmo as empresas com dificuldades na utilização de trabalho remoto, tiveram que adotar medidas para diminuir seus riscos modificando inteirações do tipo trabalhador-trabalhador por inteirações do tipo trabalhador-máquina, contribuindo, assim, para aumentar a automação.

Outro elemento a impulsionar tecnologias de automação se deve ao fato de que as atividades produtivas, em todos os ramos da economia, buscam depender cada vez menos do trabalho humano devido às recorrentes pandemias. Uma consequência disto é a postura empresarial, em escala crescente, em robotizar as rotinas de trabalho, pois: 
“...robots don't get sick. Robots and algorithms can't catch Coronavírus and so are less likely to spread it. The pandemic could therefore lead businesses to adopt those technologies in order to reduce the risk of contagion and protect both workers and consumers." (Wallace-Stephens e Morgante, 2020, p. 21)

Essas afirmações de aumento da automação decorrente da COVID-19 foram corroboradas por uma enquete realizada pela Mckinsey Global Institute, cujos resultados encontram-se na Figura 12 que se segue.

Foram entrevistados 800 executivos de negócios de nove países, para os quais foi feita a seguinte pergunta: Since the start of the COVID-19 oubreak, how was your company's or business area's adoption of the following technology trends changed?

FIGURA 12

Enquete sobre processos de automação e digitalização

Automação

Acelerado Sem

Sem
mudanca

Automação / IA

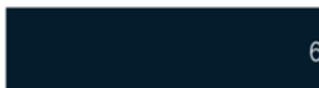

Digitalização

Digitalização para interação entre funcionários
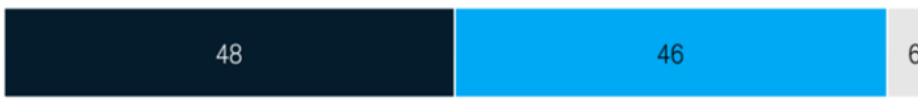

Digitalização da cadeia de abastecimento

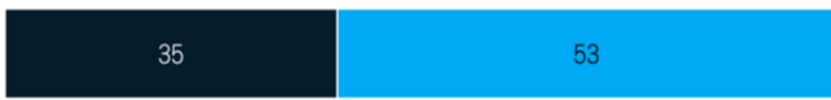

12

Fonte: McKinsey Global Institute (2021). Elaboração do autor.

Os resultados mostram que $68,0 \%$ dos executivos entrevistados indicaram que possuem planos de incrementar adoção da automação e da inteligência artificial. No caso da digitalização voltada para colaboração e inteiração de trabalhadores esta cifra chega a $85,0 \%$. Foi detectado, também, que uma ampla parcela dos executivos indicou esperarem mais desdobramentos das ferramentas digitais voltadas para o trabalho, da plataforma de e-commerce, bem como plataformas digitais nas cadeias de abastecimento. 


\subsection{A digitalização e o avanço do e-commerce}

Uma das consequências de novos processos de digitalização foi acelerar as compras e vendas na modalidade de e-commerce muito além das previsões mais otimistas, produzindo novas ocupações do tipo delivery, as quais contribuíram para compensar as perdas de empregos em outras ocupações.

Este crescimento do $e$-commerce durante a pandemia provocou a demissão de muitos trabalhadores em vendas no varejo e prestadores de serviços, ao mesmo tempo em que criou um vigoroso aumento da demanda para trabalhadores tipo delivery, assim como de outros serviços com tecnologias semelhante.

A Figura 13 revela o resultado do avanço do e-commerce para um conjunto de países selecionados. No conjunto desses oito países, a participação do e-commerce no total das vendas a varejo aumentou de duas a cinco vezes, em 2020, relativamente à média observada nos cinco anos anteriores. Essa onda de e-commerce ocorreu mais significantemente nos serviços online das lojas de departamentos, nos mercados, e na entrega de alimentos, como reflexo das pressões exercidas pelos consumidores devido à pandemia.

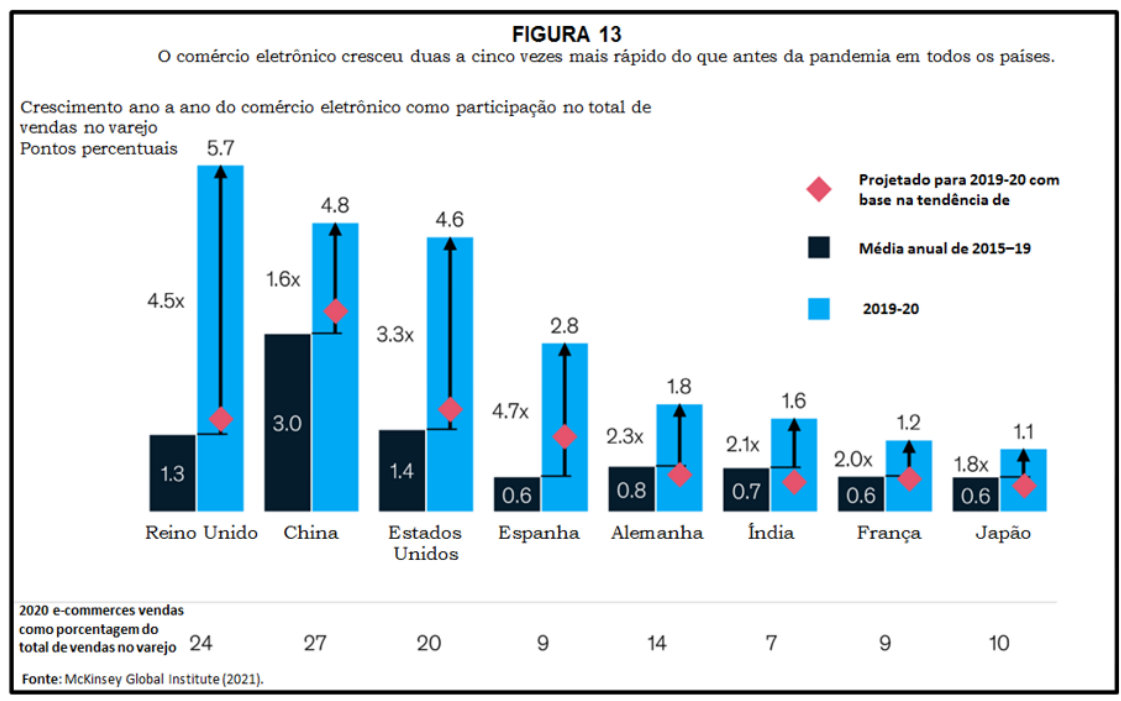

As evidências disponíveis na literatura sobre o tema indicam que o aumento pelos serviços e-commerce é muito improvável de desaparecerem. A expansão sustentada dessa modalidade promoverá uma significativa alteração entre as ocupações, com a demissão de caixas e assistentes de vendas, e criará ocupações nos setores de transportes, comunicações e armazenamento. Além disso, muitas ocupações que eram exercidas dentro das lojas muito provavelmente não retornarão. (Mcknsey Global Institute, 2021). 


\title{
6. As implicações da COVID-19 para a produtividade do trabalho
}

\subsection{A trajetória recente da produtividade global do trabalho e os efeitos da chegada da pandemia}

Para falar dessas implicações é preciso rememorar que antes do surto da COVID-19, a economia global já vinha experimentando forte declínio nos níveis de produtividade. A produtividade global do trabalho cresceu lentamente desde o inicio dos anos 2.000, tendo alcançado seu pico (2,8\%) em 2007, logo antes da crise financeira global que a fez cair para o patamar de 1,4\%, em 2016, estabilizando-se abaixo de 2,0\% nos anos de 2017 e $2018^{4}$.

A COVID-19 atingiu a economia global num momento de alta vulnerabilidade mundial, com volumes recordes de dividas, o que pode agravar as perdas de produtividade decorrente da própria pandemia. Nesse sentido, a pandemia do Coronavírus, e a severa recessão resultante, somente vieram aumentar o risco de uma queda mais acentuada no ritmo das melhorias de longo prazo buscando favorecer o crescimento da produtividade.

Assim, o provável impacto adverso da pandemia na produtividade se revela muito preocupante, pois ela é determinante para o crescimento da renda, e fundamental para a redução global e regional dos níveis de pobreza e iniquidade.

Olhando os impactos do ponto de vista das forças econômicas, a cadeia de eventos desencadeados pela COVID-19 pode ser assim resumida:

\begin{abstract}
"Severe global biological disasters such as COVID-19 can damage labor productivity affecting both supply and demand. Adverse supply side effects can occur through the depletion of labor force; the tightening of financial conditions; and the disruption of supply chain, which are an important measure for the diffusion of innovation. The COVID-19 pandemic is also weighing sharply on aggregate demand, by depressing consumer demand for goods and services, eroding business confidence and investment, and financial costs. Weaker aggregate demand can reduce the incentive for product innovation, quality improvement, slow technological progress and lower productivity." (World Bank Group, 2020, Introduction, p. 21)
\end{abstract}

Um sumário dos principais impactos negativos sobre a produtividade do trabalho da COVID-19 pode ser observado na Figura 14.

4 Estas estatísticas aparecem na publicação World Bank Group (2020). 
Figura 14: Impactos negativos da COVID-19 para a produtividade do trabalho

\section{Razão}

Enfraquecimento do comércio exterior e queda nos investimentos:

A incerteza sobre a duração da pandemia e a paisagem econômica global que eventualmente emerge dela pode desencorajar o investimento. As preocupações sobre a viabilidade em longo prazo e a resiliência das operações podem levar a um recuo das cadeias de valor globais - o que obstruiria um canal importante para a transmissão de tecnologia internacional - e desestimular o investimento estrangeiro que muitas vezes está relacionado a tais processos de produção. O investimento e o comércio desempenham papéis importantes na promoção do aumento da produtividade.

Mudança no mercado de trabalho e erosão do capital humano:

Grandes perdas de renda e interrupções na escolaridade, que afetaram mais de 90 por cento das crianças do mundo, podem aumentar as taxas de evasão e reduzir o acúmulo de capital humano para uma geração de crianças. A educação continua sendo um fator crítico do crescimento da produtividade.

Lentidão das realocações no mercado de trabalho:

Desde 1995, a realocação da mão-de-obra de setores de baixa produtividade para setores de alta produtividade respondeu por cerca de dois quintos do crescimento geral da produtividade nos países emergentes e em desenvolvimento. As restrições de mobilidade podem retardar a realocação de trabalhadores de empresas e setores de baixa produtividade para outros de alta produtividade, o que muitas vezes envolve a realocação de áreas rurais para áreas urbanas. As perdas de empregos induzidas por pandemia podem cair desproporcionalmente naqueles anteriormente ocupados em serviços de baixa remuneração e empregos no setor informal, possivelmente aumentando a desigualdade de renda e corroendo o capital humano.

\section{Pesado volume da dívida:}

Governos e corporações venceram a pandemia COVID-19 com altas dívidas já esticadas. Os balanços patrimoniais das empresas podem eventualmente dobrar em recessões induzidas pelo COVID-19, sobrecarregando os balanços dos bancos a tal ponto que pode desencadear crises financeiras. Isso levaria à obsolescência do capital, bem como grandes perdas de empregos. Perdas de produtividade duradouras decorrentes de crises financeiras estão bem documentadas e confirmadas em diversos estudos.

Fonte: World Bank Group(2020). Elaboração do autor.

Dois desses impactos se destacam. As incertezas quanto à dimensão e a duração da pandemia tendem a enfraquecer o comércio internacional, ao mesmo tempo em que os investimentos também estão caindo, sendo estes elementos fundamentais para estimular o crescimento da produtividade do trabalho.

Além disso, a pandemia tem levado, também, a profundas mudanças no mercado de trabalho, tanto quantitativamente, quanto qualitativamente, levando a uma erosão do capital humano da força de trabalho. A população de jovens e crianças tem experimentado um aumento da evasão escolar, contribuindo, assim, para a redução do acumulo de capital humano, elemento fundamental para aumentar a produtividade do trabalho.

A queda da qualidade da educação, associada à deterioração do capital humano de toda uma geração, tem efeitos deletérios na produtividade do trabalho, que podem durar gerações. De acordo com a OECD a suspensão das atividades escolares provocada pela COVID-19 deverá causar impactos de longo prazo na economia mundial, as quais podem durar até o final do século XXI: 
"Because learning loss will lead to skill loss, and the skills people have related to their productivity, gross domestic product (GDP) could be $1.5 \%$ lower on average for the remainder of the century. The present value of the total cost would amount to $69 \%$ of current GDP for the typical country." OECD (2020a, Introduction, p. 4).

Outro aspecto a ser mencionado é que desastres severos, incluindo aqueles de natureza biológica, causam danos duradouros sobre a produtividade do trabalho. Epidemias ocorridas desde o ano 2.000 (SARS, MERS, Ebola e Zika, entre outras) tiverem efeitos negativos sobre a produtividade do trabalho. Conforme mostra a Figura 15 elas reduziram a produtividade do trabalho em cerca de $4,0 \%$ depois de 4 (quatro)anos.

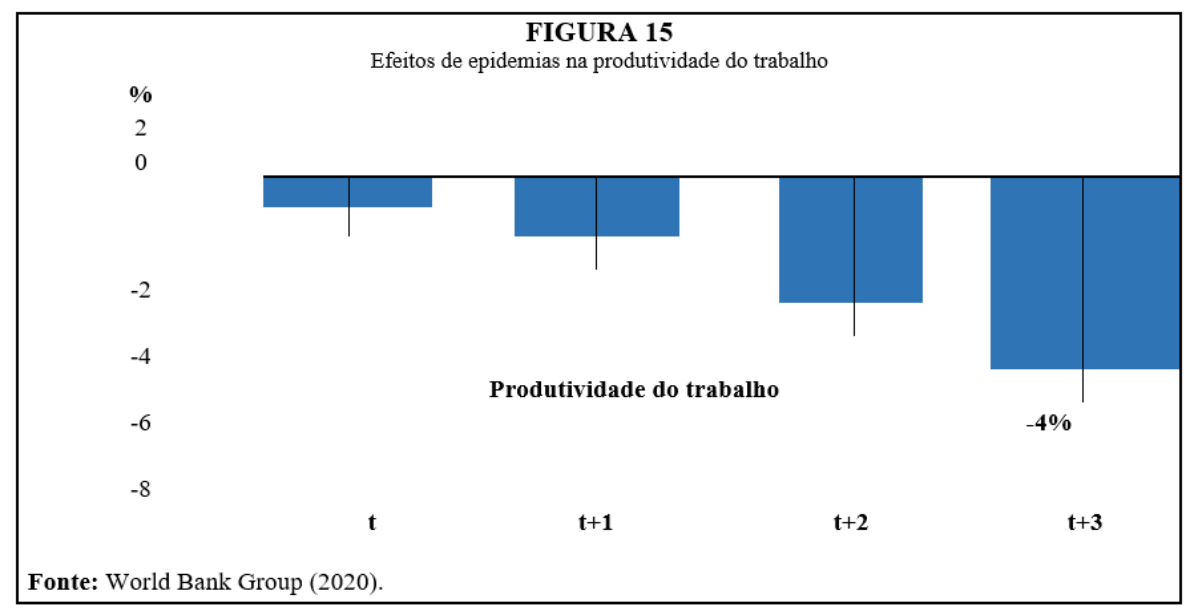

A pandemia do Coronavírus pode gerar efeitos significantemente piores do que os desastres biológicos anteriores, porque ela tem uma amplitude global e, também, pela forma de combatê-la, por meio do distanciamento social, e outras medidas bastante restritivas de contenção do vírus.

\subsection{As atividades em home office melhoraram a produtividade?}

O trabalho em home office já ocorria antes da COVID-19, e esta só fez acelerar desorganizadamente esta forma de exercer atividades laborais. Embora difícil de mensurar, a produtividade do trabalho em casa pode ter aumentado. $\mathrm{O}$ texto de Miceli, A.L. et ali (2020) traz uma resenha bastante discursiva sobre o tema, a partir da visão de empresários e trabalhadores que experimentaram essa modalidade de trabalho remoto.

Dentre as opiniões se mencionam a seguintes: ${ }^{5}$

5 Apesar de se tratar de uma revista produzida por uma Universidade de ponta (MIT), a discussão sobre o 
- Para avaliar as mudanças trazidas pelo home office forçado durante a pandemia, uma empresa com sede na Califórnia (sic!) mediu a produtividade dos seus funcionários, chegando ao resultado de aumento de 47,0\% na produtividade do trabalhador;

- No cenário da COVID-19, uma pesquisa da unidade brasileira da consultoria global da KPMG perguntou a 722 empresários de todo Brasil qual foi o impacto do home office na produtividade dos funcionários. Para a maioria $(83,5 \%)$ ela se manteve igual ou cresceu;

- Cerca de 94,0\% das empresas brasileiras afirmam que atingiram, ou superaram suas expectativas de resultados com o home office, segundo a "Pesquisa de Gestão de Pessoas na Crise da COVID-19", realizada pela Fundação Instituto de Administração, em abril de 2020, com 139 empresas brasileiras de grande, médio e pequeno porte;

- Para Nicholas Bloom, Professor do Departamento de Economia da Universidade de Stanford, a partir de uma conversa com dezenas de CEOs, gerentes seniores e formuladores de políticas sobre o futuro do trabalho, reuniu dados mostrando que, para muitos profissionais, trabalhar em casa foi um desastre para a produtividade. Isso aconteceu, entre outros motivos, devido à falta de um local apropriado para o exercício do trabalho em casa (como um aposento preparado para isso), bem como a presença de filhos na rotina de trabalho; e

- Segundo este mesmo Professor, o equilíbrio da vida profissional e pessoal, um espaço confortável e especialmente desenhado para o trabalho em domicílio, limites definidos, pausas estratégicas, e horárias de interação da equipe, representam alguns aspectos que definem os funcionários e as empresas que conseguem maximizar a produtividade de forma inovadora.

Muito embora pareça haver um predomínio de opiniões com viés para o aumento de produtividade na modalidade de home office, isto é apenas um fato em busca de um rigoroso tratamento estatístico para sua real comprovação.

\section{A COVID-19 afetará muito o desenvolvimento humano}

O mundo tem presenciado inúmeras crises sanitárias nos últimos 50 anos como, por exemplo, Sars, Mers, Zika, Ebola, assim como as de natureza econômica e financeira, como a crise de 2008/2009. Todas elas atingiram o desenvolvimento humano devastando milhões de vidas.

Mas, a humanidade, contudo, no global tem tido ganhos na área do desenvolvimento humano, ano após ano, desde o inicio da década de 1990. A pandemia deverá afetar drasticamente esta tendência, conforme mostra a Figura 16.

tema é evasiva com relação a mencionar a fonte completa das informações nela destacadas. Ainda assim se optou em apresenta-las para ilustrar esta seção. 
Isto porque a COVID-19 é distinta das crises precedentes uma vez que ela atinge, simultaneamente, o tripé renda, saúde e educação, elementos fundamentais que alicerçam o desenvolvimento humano. Como resultado as estimativas disponíveis revelam que, devido às medidas de isolamento que tem sido tomada, desde que se deu o alerta de pandemia global, indicam uma forte queda no índice de desenvolvimento humano (IDH).

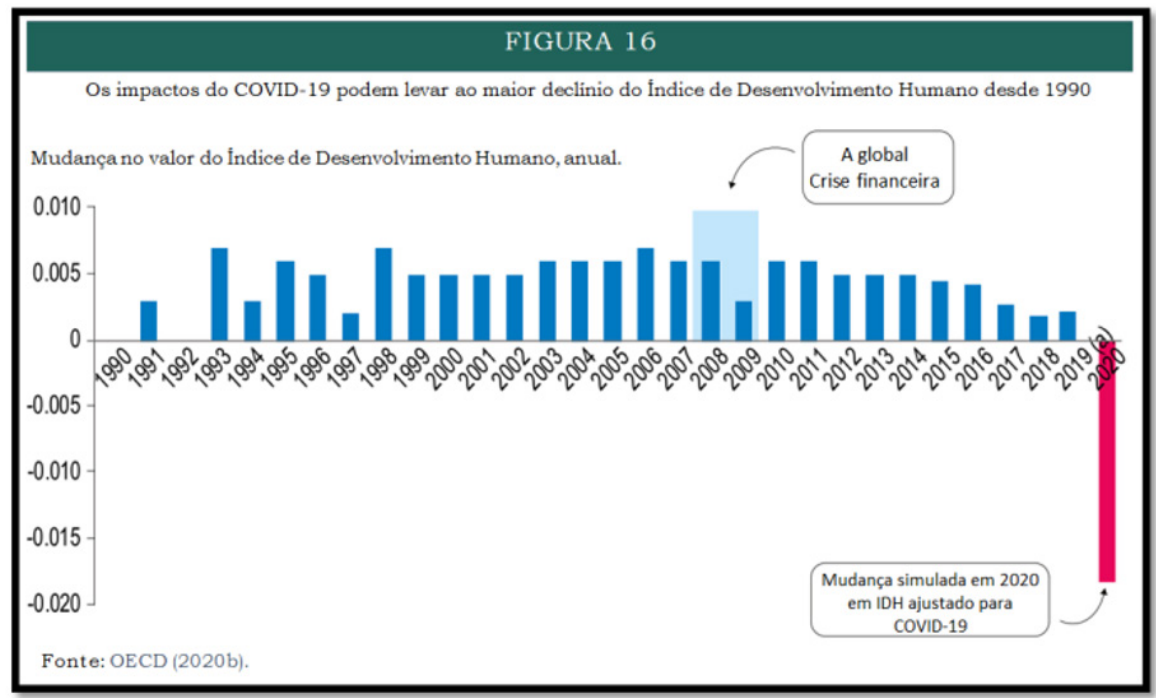

\section{Síntese conclusiva}

Desde o final de 2019 a humanidade convive com a pandemia da COVID-19, e que nos faz parecer que estamos próximos do Armagedon, tão grande é a velocidade de contaminação por Coronavírus. Este texto abordou o futuro do trabalho sob a ótica dos impactos da COVID-19 no mercado de trabalho, assim como nas relações de emprego.

Esta pandemia aumentou o risco, bem como elevou os custos (sociais e econômicos) do contato físico entre os seres humanos. Como consequência acelerou os processos de automação, do trabalho remoto, do uso da inteligência artificial, da digitalização e da robotização, todos culminando por promover uma redução geral na demanda de trabalho (elevando o desemprego), contribuindo, assim, para diminuir o ritmo de crescimento dos salários.

A produtividade do trabalho também não passará incólume aos efeitos da pandemia. Aqui, porém, os resultados globais não são tão claros. Os novos processos tecnológicos tendem a elevar a produtividade do trabalho, especialmente para o grupo dos trabalhadores qualificados que comandarão a condução desses novos processos.

Mas, por outro lado, os efeitos que o isolamento social tem causado na educação, levando à evasão e ao baixo rendimento escolar, juntamente com a erosão do 
capital humano provocado pelo aumento do desemprego de longo prazo, e as dificuldades de treinamento profissional, são fortes elementos a induzirem a um baixo nível do crescimento da produtividade, quando não sua estagnação.

Todos estes impactos somados parecem estar levando a um mundo ainda mais desigual, afetando negativamente o desenvolvimento humano, bem como um avanço ainda maior dos níveis de pobreza. Dentre os principais elementos a corroborar esta afirmação, temos o fato de que a pandemia impactou fortemente aqueles indivíduos, trabalhadores e famílias mais vulneráveis, vivendo em situações de baixa qualidade de vida, preenchendo empregos precários e vivendo na informalidade. Eles ficarão à margem dos avanços tecnológicos, dada sua baixa qualificação profissional.

Vimos, como exemplo, que o próprio trabalho remoto, especialmente, o home office, poderá ser um elemento de desigualdade intrageracional de renda, pois o trabalhadores jovens, aqueles pouco educados, os menos experientes possuem um baixo índice de teletrabalho. Isto os leva a auferirem rendas menores relativamente àqueles com maiores possibilidades de realizarem trabalho remoto.

Além disso, a possibilidade de realizar trabalho remoto varia muito entre os setores da atividade econômica. Uma consequência disto é que deverá haver um diferencial de renda em desfavor daqueles setores e ocupações que possuem maiores dificuldades em exercerem o trabalho em sua residência.

\section{Referências}

Blundel, J. e Machin, S. (2020), Self-employment in the Covid-19 crisis, $\boldsymbol{A}$ CEP Covid-19 analysis, Paper No.003, Centre for Economic Performance, London School of Economics and Political Science, May, London. https://cep.lse.ac.uk/pubs/download/cepcovid-19-003.pdf

Brussevich, Dabla-Norris e Khalid, S. (2020), Who will Bear the Brunt of Lockdown Policies? Evidence from Tele-workability Measures Across Countries, IMF Working Paper, WP/20/88, Asia and Pacific Department, June, Washington. https://www.imf. org/ /media/Files/Publications/WP/2020/English/wpiea2020088-print-pdf.ashx

Chahad, J.P.Z (2021), A Pandemia da Covid-19 e a Recessão Global: Dimensão e Impactos Socioeconômicos, Boletim Informações FIPE, No.482, Novembro, Fundação Instituto de Pesquisas Econômicas, São Paulo. https://downloads.fipe.org.br/publicacoes/bif/bif482.pdf

ILO (2020), Teleworking during the COVID-19 pandemic and beyond -A practical guide, Geneva: International Labour Office, July 2020. https://www.ilo.org/wcmsp5/ groups/public/---ed_protect/---protrav/---travail/documents/instructionalmaterial/ wcms_751232.pdf 
Korinek, A. e Stiglitz, J.E., (2021), Covid-19 driven advances in automation and artificial intelligence risk exacerbating economic inequality, BMJ 2021; 372: n. 367, March, USA. https://doi.org/10.1136/bmj.n367

Miceli, A.L. et alli (2020), Work Anywhere, MIT Technology Review, ano 01, número 01, Special Edition Home Office, Dezembro. https://mittechreview.com.br/wp-content/uploads/2021/01/mit_trbr_special_edition_home_office.pdf

Mckinsy Global Institute (2021), The future of work after COVID-19, The postpandemic economy, February, USA. https://www.mckinsey.com/featured-insights/ future-of-work/the-future-of-work-after-covid-19

OECD (2020a), The impact of COVID-19 on education - insights from education at glance 2020, Andreas Schleicher (org), OECD Publishing, Paris. https://www.oecd. org/education/the-impact-of-covid-19-on-education-insights-education-at-a-glance-2020.pdf

OIT Brasil (2020), Chaves para teletrabalho eficaz durante a pandemia COVID-19, Março, Brasília. https://www.ilo.org/brasilia/noticias/WCMS_740097/lang--pt/index.htm.

Smith, E. e Smith, R. (2020), Artificial Intelligence (AI) and An Infection: how Covid-19 is accelerating the future of work, International Development LSE blog, London School of Economics and Political Science, London.

Wallace-Stephens, F. e Morgante, E. (2020). Who is at risk, work and automation, in the time of Covid-19, Royal Society of Arts, manufactures and commerce, October, London.

World Bank Group (2020), Global Productivity - Trends, Drivers and Policies, Edited by Alistair Dieppe, Advance Edition, Washington, USA.

World Economic Forum (2020a), Resetting the Future of Work Agenda: Disruption and Renewal in a Post-COVID World, White Paper, October, Genève.

World Economic Forum (2020b), The Future of Jobs Report, October, Genève. http:// www3.weforum.org/docs/WEF_Future_of_Jobs_2020.pdf. São Paulo, maio de 2021. 